\title{
The performance of COR optimization using different constraint handling strategies to solve ELD
}

\author{
Azralmukmin Azmi ${ }^{1}$, Samila Mat Zali ${ }^{2}$, Mohd Noor Abdullah ${ }^{3}$, Mohammad Faridun Naim Tajuddin ${ }^{4}$, \\ Siti Rafidah Abdul Rahim ${ }^{5}$ \\ ${ }^{1,2,4,5}$ School of Electrical System Engineering, Universiti Malaysia Perlis (UniMAP), Malaysia \\ ${ }^{3}$ Green and Sustainable Energy (GSEnergy) Focus Group, Faculty of Electrical and Electronic Engineering, \\ Universiti Tun Hussein Onn Malaysia (UTHM), Malaysia
}

\begin{tabular}{|c|c|}
\hline Article Info & ABSTRACT \\
\hline Article history: & \multirow{10}{*}{$\begin{array}{l}\text { This research compares the performance of Competitive Over Resources } \\
\text { (COR) optimization method using a different type of constraint handling } \\
\text { strategy to solve the economic load dispatch (ELD) problem. Previously, } \\
\text { most research focused on proposing various optimization techniques using } \\
\text { the Penalty Factor Strategy (PFS) to search for a better global optimum. } \\
\text { The issue using the penalty factor is that it is difficult to find the correct tune } \\
\text { of constant value that influences the algorithm to find the solution. The other } \\
\text { technique is using Feasible Solution Strategy (FSS), the idea of which is to } \\
\text { locate the infeasible particle to the feasible solution and avoid being trapped } \\
\text { by the unsuccessful condition of constraint. This paper investigates the } \\
\text { performance of PFS and FSS on the COR optimization method for solving } \\
\text { ELD. Both strategies have been tested on two standard test systems to } \\
\text { compare the performance in terms of a global solution, robustness and } \\
\text { convergence. The simulation shows that FSS is a better solution compared } \\
\text { to PFS. }\end{array}$} \\
\hline Received Apr 28, 2019 & \\
\hline Revised Jun 30, 2019 & \\
\hline Accepted Jul 14, 2019 & \\
\hline Keywords: & \\
\hline Competitive over resources & \\
\hline Constraint handling & \\
\hline Economic load dispatch & \\
\hline Feasible solution strategy & \\
\hline Optimization & \\
\hline
\end{tabular}

Copyright $@ 2020$ Institute of Advanced Engineering and Science. All rights reserved.

\section{Corresponding Author:}

Azralmukmin Azmi,

School of Electrical System Engineering,

Universiti Malaysia Perlis (UniMAP),

Kampus UniMAP Pauh Putra, 02600 Arau, Perlis, Malaysia.

Email: azralmukmin@unimap.edu.my

\section{INTRODUCTION}

The economic load dispatch (ELD) of generation is one of the most crucial tasks in modern power systems. It promises better dispatch scheduling to mitigate the increasing cost of fuel for various types of thermal power plant. Solving the ELD problem is a potentially significant economic solution to power system planning and operations. ELD's goal is to commit the required power consumption by planning the different types of power generation units such that secure total cost production is the cheapest possible while fulfilling the system's equality and inequality constraints. It keeps the cost of producing electricity to a minimum price by properly allocating workloads among the generating units of the plants with various operating efficiencies, type of fuel cost and total transmission losses of systems. This optimum solution to the problem of generating power contributes significant economic benefits to the operation of the power plant.

Initially, the ELD problem was solved using traditional techniques such as linear, quadratic and nonlinear programming methods as provided in [1-5]. The conventional techniques have a higher probability of becoming trapped in local minima solution due to the complex fuel cost function problem related to the highly nonlinear characteristic of present power generating units such as ramp rate limit and prohibited operating zones. Nowadays, in order to handle the nonlinear fuel cost function, many advanced optimization techniques based on nature-inspired meta-heuristic has been implemented on ELD such as 
Genetic Algorithm [6], Particle Swarm Optimization [7], Artificial Bee Colony [8, 9], and Ant Colony Optimization [10], Cuckoo Search Algorithm [11, 12], to name a few.

In 2014, Mohseni, Gholami, Zarei and Zadeh [13] introduced a new meta-heuristic algorithm called Competition Over Resources (COR), inspired by a group of animal communities which compete for resources. The COR algorithm was evaluated for quality results by addressing various literature optimization issues in $[14,15]$. From the literature, the COR algorithm is used to evaluate eight different benchmark features and concludes that this optimization method aims to be a global solution better than the PSO and GA algorithms. COR also has been tested for its capacity to address the ELD problem in [16] to find the optimal generating costs on 6-unit and 15-unit test systems.

One crucial problem while applying Optimization to the ELD problem is that the solutions will not always satisfy the inequality and equality constraints simultaneously. Most ELD constraint optimization problems have adopted the Penalty Function Strategy (PFS) approach [17-21] to handling constraints because of its simple implementation. The penalty function approach involves several penalty parameters which need carefully determined tuning value to obtain a feasible solution. This approach needs extensive experimentation for setting up the appropriate parameters needed to define the correct penalty function parameter. This paper proposed a Feasible Solution Strategy (FSS), which prevents the creation of the infeasible solution. Using the FSS method, the infeasible particle will be relocated to new particles until a feasible solution condition is satisfied.

This paper compares the performance of COR using PFS and FSS to achieve a quality solution for the ELD problem. Due to simulation based on practical operating conditions of the power system, the equality and non-equality constraints is considered, which increased complexity in search for a quality solution. The objective of using PFS and FSS with COR optimization to overcome the ELD issue is to compare the performance with other optimization techniques in terms of its quality as a global solution and convergence capability.

\section{ELD PROBLEM FORMULATION}

The ELD issue, which deals extensively with financial concerns, refers to the amount of power to be assigned from all generators in an attempt to minimize the cost of supplying the required electrical energy subject to several constraints of multiple generating units. The ELD's mathematical optimization has three primary parts, which are the optimization variable of the problem, the goal of the objective function and constraints.

\subsection{Optimization Variable}

The optimized input variable is the real output power of generating units,

$$
P=\left[P_{1}, P_{2}, \ldots, P_{N g}\right]
$$

Where, $N g$ is the total number of generating unit in the power system.

\subsection{Objective Function}

The objective function of ELD is to supply power via each generator unit for the request demand load with minimum generation total fuel cost. ELD's objective function can be expressed through the problem of mathematical optimization,

$$
\operatorname{minimize} F_{c o s t}=\sum_{j=1}^{N g} F_{j}\left(P_{j}\right)
$$

Where

$F_{j}\left(P_{j}\right) \quad=$ generation cost of the $j^{\text {th }}$ generator $(\$ / \mathrm{h})$

$P_{j} \quad=$ power of the $j^{\text {th }}$ generator (MW)

Moreover, the cost coefficient of each generator stated as,

$$
F_{j}\left(P_{j}\right)=\alpha_{j}+\beta_{j} P_{j}+\gamma_{j} P_{j}^{2}
$$

Where,

$\alpha_{j}, \beta_{j}$ and $\gamma_{j}=$ coefficients of the $j^{\text {th }}$ generating unit 


\subsection{Constraints} constraints:

To achieve ELD's optimum value, the objective function has been subject to the following limitation

\subsubsection{Power Demand Constraint}

Total power generation must be satisfied with the total power demand and power losses as follows,

$$
\sum_{j=1}^{N g} P_{j}=P_{D}+P_{L}
$$

Where,

$\sum_{j=1}^{N g} P_{j} \quad=$ Total power generation (MW)

$P_{D} \quad=$ Total power demand (MW)

$P_{L} \quad=$ Total power transmission loss (MW) using Kron's loss formula

The total power transmission losses calculated as follows,

$$
P_{L}=\sum_{j=1}^{N g} \sum_{k=1}^{N g} P_{j} B_{j k} P_{k}+\sum_{j=1}^{N g} P_{j} B_{j 0}+B_{00}
$$

Where,

$B_{j k}, B_{j 0}, B_{00}=$ B-coefficients or loss coefficients.

\subsubsection{Generation Constraint}

Each generator's power generation must be within its operating limits as follows,

$$
\boldsymbol{P}_{j}^{\min }<\boldsymbol{P}_{j}<\boldsymbol{P}_{j}^{\max }
$$

Where, $P_{j}^{\min }$ and $P_{j}^{\max }$ is minimum and maximum generation limit in MW.

\subsubsection{Prohibited Operating Zones}

The system involves certain restricted areas related to physical component constraints as follows,

$$
\begin{aligned}
& P_{P O Z, j}^{\min } \leq P_{P O Z, j} \leq P_{P O Z, j, 1}^{l} \\
& P_{P O Z, j, k-1}^{u} \leq P_{P O Z, j} \leq P_{P O Z, j, 1}^{l}, k=2,3, \ldots, n_{j} \\
& P_{P O Z, j, n_{j}}^{u} \leq P_{P O Z, j} \leq P_{P O Z, j}^{\max }
\end{aligned}
$$

Where,

$P_{P O Z, j, k}^{l}=$ minimum border of $k^{\text {th }}$ restricted zone of the $\mathrm{j}^{\text {th }}$ generator

$P_{P O Z, j, k}{ }^{u}=$ maximum border of $k^{\text {th }}$ restricted zone of the $j^{\text {th }}$ generator

$n_{j} \quad=$ number of restricted zones of the $j^{\text {th }}$ generator

\subsubsection{Ramp Rate Limits}

The operating range of all operating units is restricted by their ramp rate limits in the actual power generation process for each unit. An increase or decrease of power generation is as follows,

$$
\begin{aligned}
& P_{R R L, j}-P_{R R L, j}{ }^{0} \leq U R_{j} \\
& P_{R R L, j}{ }^{0}-P_{R R L, j} \leq D R_{j} \\
& \max \left(P_{R R L, j}{ }^{\min }, P_{R R L, j}{ }^{0}-D R_{j}\right) \leq P_{R R L, j} \leq \min \left(P_{R R L, j}{ }^{\max }, P_{R R L, j}{ }^{0}-U R_{j}\right)
\end{aligned}
$$

Where,

$U R_{j} \quad=$ up ramp limit of the $j^{\text {th }}$ generator $(\mathrm{MW} / \mathrm{h})$

$D R_{j} \quad=$ down ramp limit of the $j^{\text {th }}$ generator $(\mathrm{MW} / \mathrm{h})$

$P_{R R L, j}{ }^{0}=$ previous output power of the $j^{\text {th }}$ generator $(\mathrm{MW} / \mathrm{h})$ 


\section{COR OPTIMIZATION ALGORITHM FOR ELD}

The COR begins at each year with the groups divided based on the food supply for each territory. At this stage, each group is looking for food in its territory. An active participant will periodically remove the weaker participant from the same region throughout the process so that the final process will consist of excellent competitors only. When food sources in a particular field are reduced, the members of the group will also be decreased. Members possibly will migrate to join a group in regions where there is plenty of food resources. Finally, the group with fewer resources is eliminated at the end of the year, leaving only the group with the most food sources. Figure 1 shows the pseudo-code of the COR optimization algorithm implementation to solve the ELD problem.

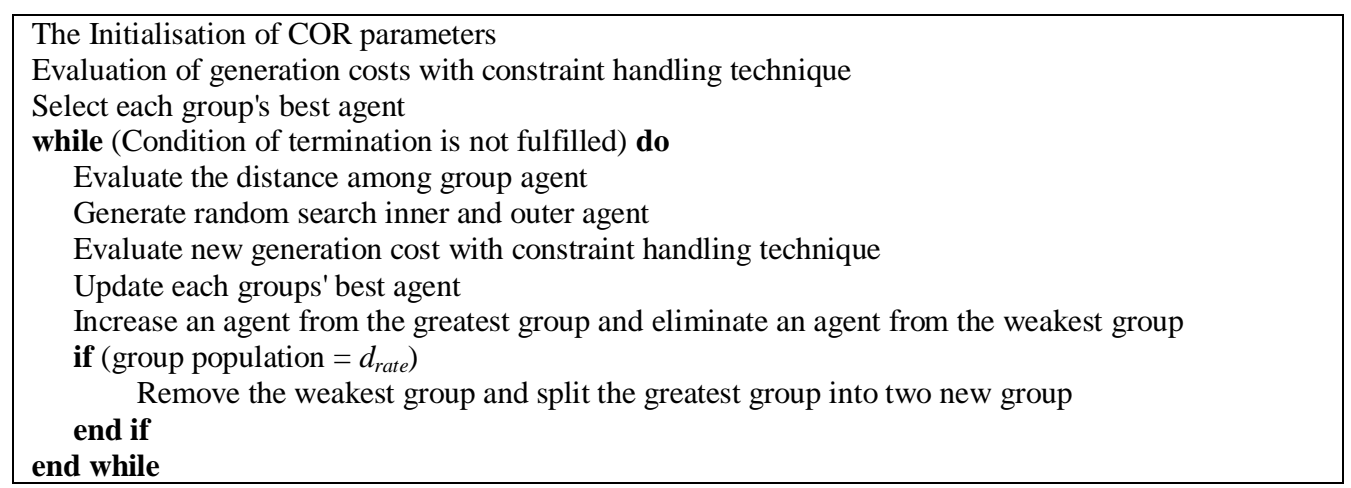

Figure 1. Pseudocode for COR optimization algorithm

\subsection{Initialisation}

Identify parameters of COR such as minimum $\left(P_{\min }\right)$ and maximum $\left(P_{\max }\right)$ generation limit of each unit, number of iterations $\left(N_{\text {iter }}\right)$, number of population $\left(N_{\text {pop }}\right)$, number of groups $\left(N_{\text {group }}\right)$, rate of death $\left(d_{\text {rate }}\right)$ outer searching factor $\left(D_{s c h}\right)$ and population ratio between inner/outer neighborhood $\left(P_{s c h}\right)$. The generator's active power generation is identified as an ELD problem input variable. Then, the population was randomly distributed, ranging over their maximum and minimum limit according to the generator limit stated in (6).

\subsection{Evaluation of Generation Cost with Constraint Handling Technique}

The fitness of each population is assessed with the objective function in (2) using the Penalty Factor Strategy (PFS) or Feasible Solution Strategy (FSS). The result of the fitness cost calculation is graded from the highest to the lowest solution. Then, the agents were equally distributed into the number of groups, $N_{\text {group }}$ and the best solution was identified as the best group agent for each group.

\subsubsection{Penalty Factor Strategy (PFS)}

This strategy penalizes ineffective solutions by multiplying a persistent penalty for these alternatives that violate the limitations. To satisfy constraint limitation and disallow the workable area, the individual population's fitness performance is measured using (9), which is the combination of objective function equation between (2) and PFS linked with related constraints. This evaluation feature is used to obtain the smallest cost generation value while fulfilling the limitation of equality and non-equality constraint problem, as stated in (4-8).

$$
f\left(P_{j}\right)=\sum_{j=1}^{N g} F_{j}\left(P_{j}\right)+k_{1} \cdot\left|\sum_{j=1}^{N g} P_{j}-\left(P_{D}+P_{L}\right)\right|+k_{2} \cdot \sum_{j=1}^{N g} P_{P O Z, j}+k_{3} \cdot \sum_{j=1}^{N g} P_{R R L, j}
$$

Where:

$k 1, k 2, k 3=$ constraint constant value

\subsubsection{Feasible Solution Strategy (FSS)}

The PFS technique does not ensure that all solutions generated by the optimization algorithm meet the limitations of equality constraint because it is exceedingly difficult to obtain when considering nonlinear problems in ELD. Using FSS, handling constraints based on the repair of the unfeasible solution is implemented to guarantee that all the solutions generated are satisfactory through the optimization process. The details of FSS procedure is shown in Figure 2. 


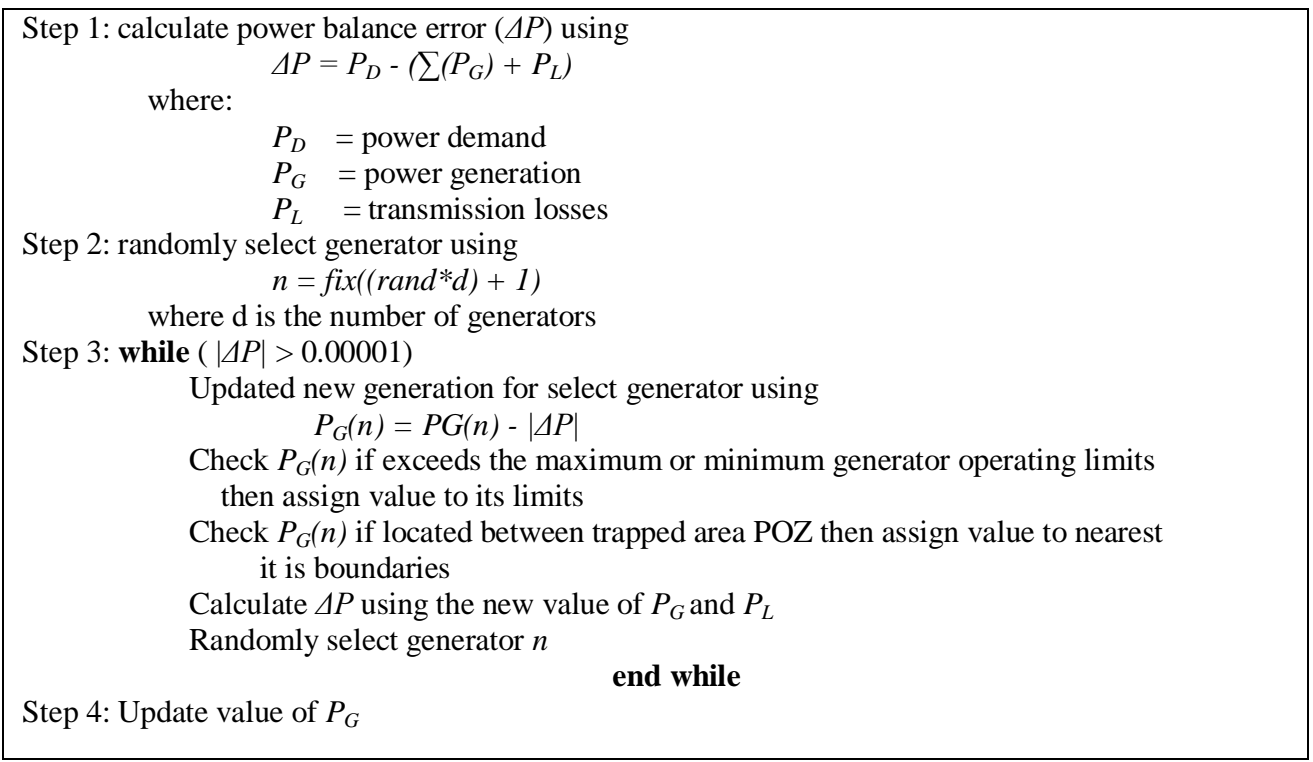

Figure 2. Constraint handling based on FSS

\subsection{Determination of Territory}

Each group's territory is described by using the Euclidean distance among the most excellent agents in the group. The minimum value of the distance between territories, $d^{\min }$ is the option rate to specify inner territory. The maximum and minimum power generation boundary for inner territory determined in (10),

$$
\begin{aligned}
& P_{\text {inner }}^{\min }=P_{j}-d^{\min } \\
& P_{\text {inner }}^{\max }=P_{j}+d^{\min }
\end{aligned}
$$

The maximum and minimum power generation for outer territory determine in (11),

$$
\begin{aligned}
& P_{\text {outer }}^{\min }=P_{j}-\left(d_{\text {sch }} \times l\right) \\
& P_{\text {outer }}^{\max }=P_{j}+\left(d_{\text {sch }} \times l\right)
\end{aligned}
$$

Where $l$ is the different value between $P_{\max }$ and $P_{\min }$ and $d_{s c h}$ is the option rate of the outer space search capability between 0 and 1 .

\subsection{New Population Generation and Evaluation}

The population quantity between the inner and outer territories of each group must be determined using the ratio of inner and outer neighbourhoods, $P_{s c h}$. Some quantity of the agent's new population in the group was produced randomly using the inner territory to locate a prospective optimum area within the group boundary. The left agent is obtained randomly using the identified outer territory with a larger searching space area to raise the opportunities of a random agent discovering optimal region outside group margins.

Finally, the new generated agents are set to the maximum and minimum boundary shown in (6). Then, all agents are evaluated using the process details in step 3.2 and update the position of the new best group agent.

\subsection{Update Group Members}

The group with the highest results from one of the group members will add a new member to its community while the poorest-performing group will eliminate one of its members. The competitive organization will increase its population from this process, to discover potential wealthy assets and the least productive organization will reduce its members. 


\subsection{Termination Condition}

This ELD optimization problem uses the number of iterations, $N_{\text {iter }}$ as an ending criterion for the process. The COR algorithm ends the process when the highest iteration is accomplished, and the optimal result is recorded. Else, this process in step 3.3 is repeated.

\section{RESULTS AND ANALYSIS}

The PFS and FSS constraints handling approaches for the ELD problem have been tested using the COR algorithm on two standard different test systems in order to compare their performances. All simulation work is carried out with MATLAB programming on a PC specification with an Intel Core i7 Dual-core $2.80 \mathrm{GHz}, 8 \mathrm{~GB}$ RAM. For all test cases, the population size is set to 100,200 maximum iterations and run 30 times, respectively. The parameters setting for COR used for both case studies are listed in Table 1.

\subsection{6-Unit Test System}

This case study comprises six generators together with constraints of ramp rate limits, real power balanced, prohibited operating zones, and generating limits. Total active power demand is $1263 \mathrm{MW}$, and transmission loss is accounted in this test. The parameter of this test system is obtained from [22], and the results are compared for the cases of GA [22], PSO [22], and NPSO-LRS [23].

Table 1 demonstrates the statistical results attained after 30 runs of PFS and FSS. The result shows that the COR-FSS method can produce a better solution on the minimum cost compared with COR-PFS and other optimization techniques. Except for GA, all the other algorithms give almost the same minimum generation cost of COR-FSS. Both COR-PFS and COR-FSS satisfied the system constraints.

For robustness test, the dominance of the COR-FSS over COR-PFS, GA and PSO can be observed. The maximum cost and average cost values obtained by COR-FSS are very close to the minimum cost value and the lowest value of the standard deviation (SD). Result proves that COR-FSS is more robust and constitutes a more consistent solution compared to other techniques.

Table 1. Optimal Results for the 6-Unit Test System

\begin{tabular}{|c|c|c|c|c|c|}
\hline \multirow{2}{*}{ Power Generation (MW) } & \multicolumn{5}{|c|}{ Optimization Method } \\
\hline & GA & PSO & NPSO-LRS & COR-PFS & COR-FSS \\
\hline $\mathrm{G}_{1}$ & 474.81 & 447.50 & 446.96 & 448.0018 & 447.4870 \\
\hline $\mathrm{G}_{2}$ & 178.64 & 173.32 & 173.39 & 173.0716 & 173.3266 \\
\hline $\mathrm{G}_{3}$ & 262.21 & 263.47 & 262.34 & 264.6342 & 263.4636 \\
\hline $\mathrm{G}_{4}$ & 134.28 & 139.06 & 139.51 & 138.4441 & 139.0714 \\
\hline $\mathrm{G}_{5}$ & 151.90 & 165.47 & 164.71 & 165.4049 & 165.4668 \\
\hline $\mathrm{G}_{6}$ & 74.18 & 87.13 & 87.98 & 86.4171 & 87.1427 \\
\hline Total Power Generated & $1,276.03$ & $1,276.01$ & $1,275.94$ & $1,275.9737$ & $1,275.9586$ \\
\hline Power Losses (Ploss) & 13.02 & 12.96 & 12.94 & 12.9737 & 12.9586 \\
\hline Total Generation Cost $(\$ / \mathrm{h})$ & 15,459 & 15,450 & 15,450 & $15,449.9235$ & $15,449.8994$ \\
\hline Minimum Cost & 15,459 & 15,450 & - & $15,449.9235$ & $15,449.8994$ \\
\hline Maximum Cost & 15,524 & 15,492 & - & $15,478.9031$ & $15,449.8995$ \\
\hline Average Cost & 15,469 & 15,454 & - & $15,460.6548$ & $15,449.8994$ \\
\hline $\mathrm{SD}$ & 0.0570 & 0.0002 & - & 7.5517 & $3.3043 \mathrm{e}-05$ \\
\hline
\end{tabular}

Figure 3 shows the convergence performance between COR-FSS and COR-PFS for achieving the best solution cost. It shows that the COR-FSS strategy reaches the lowest cost of generation quicker than COR-PFS. COR-FSS generates the lowest cost in the initial iteration since it can eliminate the conditional of constraint generation compared to COR-PFS, which is affected by the penalty factor for not exceeding the conditional of constraint. 


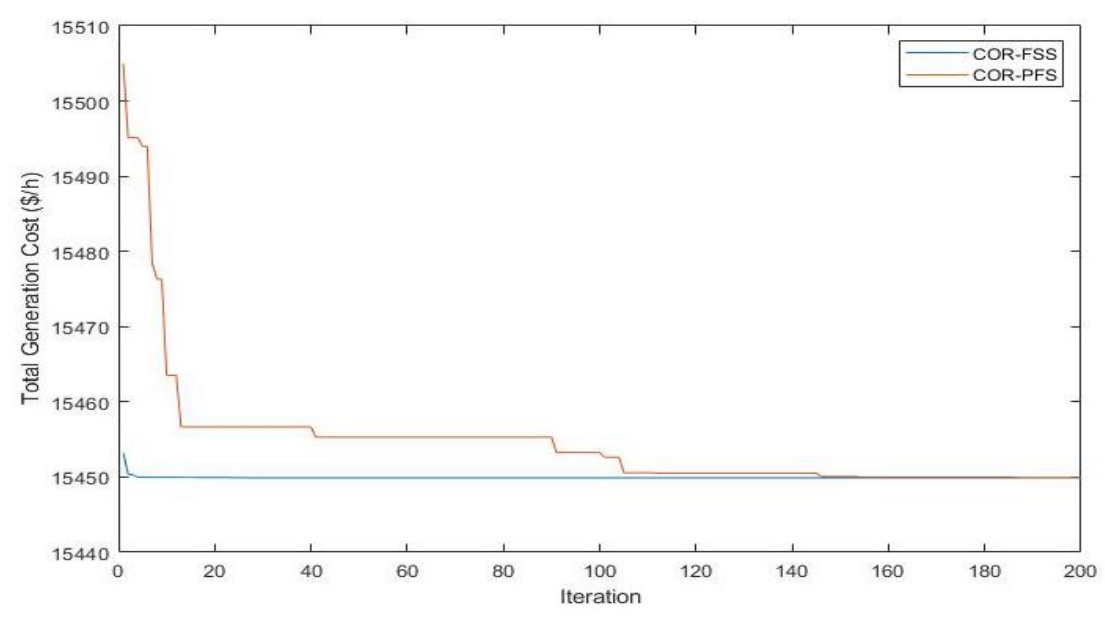

Figure 3. Convergence behaviour of COR-FSS and COR-PFS for 6-unit test systems

\subsection{5-Unit Test System}

This case study consists of 15 generating units of large-scale test systems with a total active load demand of $2630 \mathrm{MW}$. It also considers the ramp rate limits, real power balanced with transmission losses, prohibited operating zones, and generating limits. The parameters of this test system are obtained from [22], and the results are compared with the cases of GA [22], PSO [22], ABC [24] and GA-API [25].

The statistical results of maximum, minimum and average cost achieved after 30 individual runs of PFS and FSS are based on the COR algorithm and compared with other methods as shown in Table 2. The result shows that COR-FSS obtained the best global solution with the value of $32,704.4499 \$ / \mathrm{h}$, followed by COR-PFS by $32,717.0105 \$ / \mathrm{h}$. Both techniques satisfied the limitation set by the test system constraints. It observed that the COR-FSS technique could produce better quality solution generation cost and the lowest value of standard deviation among all stated technique.

The COR-FSS technique produced the lowest standard deviation (SD) with the value of $3.3154 \times 10^{-4}$ compared to COR-PFS. However, COR-PFS' value of standard deviation is higher than GA, PSO, ABC and GA-API. COR-PFS demonstrated its capability to obtain robust and consistent minimum results of cost generation solution.

Figure 4 shows the convergence behaviour of COR-PFS and COR-FSS for a maximum iteration of 200. COR-FSS achieved the lowest cost generation in the early iteration of 20 and gradually move towards optimal results by the end of iteration, which is much faster compared with COR-PFS.

Table 2. Optimal Results for the 15-Unit Test System

\begin{tabular}{|c|c|c|c|c|c|c|}
\hline \multirow{2}{*}{ Power Generation (MW) } & \multicolumn{6}{|c|}{ Optimization Method } \\
\hline & GA & PSO & $\mathrm{ABC}$ & GA-API & COR-PFS & COR-FSS \\
\hline $\mathrm{G}_{1}$ & 415.31 & 439.11 & 454.2778 & 454.70 & 454.7253 & 455.0000 \\
\hline $\mathrm{G}_{2}$ & 359.72 & 407.97 & 369.7131 & 380.00 & 379.3048 & 380.0000 \\
\hline $\mathrm{G}_{3}$ & 104.43 & 119.63 & 130.0000 & 130.00 & 129.9789 & 130.0000 \\
\hline $\mathrm{G}_{4}$ & 74.99 & 129.99 & 124.3210 & 129.53 & 129.7756 & 130.0000 \\
\hline $\mathrm{G}_{5}$ & 380.28 & 151.07 & 163.1341 & 170.00 & 169.1184 & 170.0000 \\
\hline $\mathrm{G}_{6}$ & 426.79 & 460.00 & 460.0000 & 460.00 & 459.9703 & 460.0000 \\
\hline $\mathrm{G}_{7}$ & 341.32 & 425.56 & 405.4317 & 429.71 & 430.0000 & 430.0000 \\
\hline $\mathrm{G}_{8}$ & 124.79 & 98.57 & 85.6483 & 75.35 & 103.7853 & 71.7561 \\
\hline $\mathrm{G}_{9}$ & 133.14 & 113.49 & 92.1289 & 34.96 & 48.9414 & 58.9054 \\
\hline $\mathrm{G}_{10}$ & 89.26 & 101.11 & 157.4626 & 160.00 & 133.7865 & 160.0000 \\
\hline $\mathrm{G}_{11}$ & 60.06 & 33.91 & 74.5293 & 79.75 & 79.2430 & 80.0000 \\
\hline $\mathrm{G}_{12}$ & 50.00 & 79.96 & 79.8057 & 80.00 & 79.8047 & 80.0000 \\
\hline $\mathrm{G}_{13}$ & 38.77 & 25.00 & 25.0000 & 34.21 & 25.0048 & 25.0000 \\
\hline $\mathrm{G}_{14}$ & 41.94 & 41.41 & 19.3117 & 21.14 & 18.2376 & 15.0000 \\
\hline $\mathrm{G}_{15}$ & 22.64 & 35.61 & 20.8153 & 21.02 & 18.7265 & 15.0000 \\
\hline Total Power Generated & $2,668.40$ & $2,662.40$ & $2,661.5795$ & $2,660.36$ & $2,660.4030$ & $2,660.6615$ \\
\hline Power Losses (Ploss) & 38.28 & 32.43 & 31.5795 & 30.36 & 30.4042 & 30.6615 \\
\hline Total Generation Cost $(\$ / \mathrm{h})$ & 33,113 & 32,858 & $32,787.8365$ & $32,732.95$ & 32,717.010 & 32,704.4499 \\
\hline Minimum Cost & 33,113 & 32,858 & $32,787.8365$ & - & $32,717.0105$ & $32,704.4499$ \\
\hline Maximum Cost & 33,337 & 33,331 & - & - & $32,981.0896$ & $2,704.4535$ \\
\hline Average Cost & 33,228 & 33,039 & $32,791.5366$ & - & $32,794.4522$ & $32,704.4503$ \\
\hline $\mathrm{SD}$ & 0.0087 & 0.0070 & 2.4746 & - & 44.2100 & $3.3154 \mathrm{e}-4$ \\
\hline
\end{tabular}




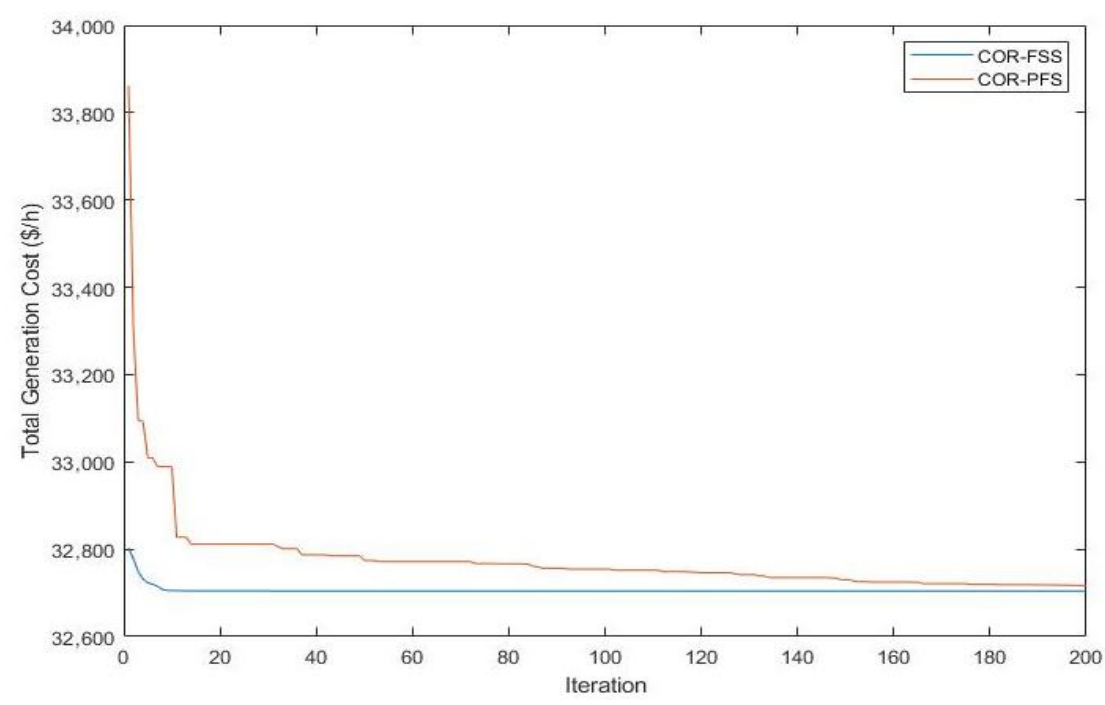

Figure 4. Convergence behaviour of COR-FSS and COR-PFS for the 15-unit test systems

\section{CONCLUSION}

This paper comparatively studies the performance of two types of constraint handling techniques, which are PFS and FSS on COR optimization technique to solve the issue of non-convex ELD problem considering generator limit, power balanced, ramp rate limits and prohibited zones. The two test system is used to testify the effectiveness of the proposed method. Based on this research, the constraint handling technique affects the optimization algorithm efficiency of finding better quality solutions. Comparing the outcomes acquired from the COR-PFS and COR-FSS demonstrated that the COR-FSS technique is highly efficient in continuously offering superior solutions in term of searching for a global solution, quick convergence and robustness for non-convex ELD issues compared to COR-PFS and other optimization techniques.

\section{ACKNOWLEDGEMENTS}

The author would like to acknowledge the Universiti Malaysia Perlis (UniMAP) and Ministry of Education Malaysia for supporting this research work under the Fundamental Research Grant Scheme (FRGS) with project code FRGS/1/2017/TK10/UNIMAP/02/10.

\section{REFERENCES}

[1] K. Iba, H. Suzuki, K. Ichi Suzuki, and K. Suzuki, "Practical Reactive Power Allocation/Operation Planning using Successive Linear Programming," IEEE Trans. Power Syst., vol. 3, no. 2, pp. 558-566, May 1988.

[2] C. E. Lin and G. L. Viviani, "Hierarchical Economic Dispatch for Piecewise Quadratic Cost Functions," IEEE Trans. Power Appar. Syst., vol. PAS-103, no. 6, pp. 1170-1175, Jun. 1984.

[3] A. Sasson, "Nonlinear Programming Solutions for Load-Flow, Minimum-Loss, and Economic Dispatching Problems," IEEE Trans. Power Appar. Syst., vol. PAS-88, no. 4, pp. 399-409, Apr. 1969.

[4] J. P. Zhan, Q. H. Wu, C. X. Guo, and X. X. Zhou, "Fast lambda-Iteration Method for Economic Dispatch With Prohibited Operating Zones,” IEEE Trans. Power Syst., vol. 29, no. 2, pp. 990-991, Mar. 2014.

[5] R. Ramanathan, "Fast Economic Dispatch Based on the Penalty Factors From Newton's Method," IEEE Trans. Power Appar. Syst., vol. PAS-104, no. 7, pp. 1624-1629, Jul. 1985.

[6] H. Vennila, B. G. Malini, V. E. Jeba, and T. R. D. Prakash, "Economic Emission Dispatch of Thermal Generating Units using Genetic Algorithm Technique,” Int. J. Enterp. Netw. Manag., vol. 4, no. 4, p. 344, 2011.

[7] M. N. Abdullah, N. A. Rahim, A. H. A. Bakar, H. Mokhlis, H. A. Illias, and J. J. Jamian, "Efficient Evolutionary Particle Swarm Optimization Approach for Nonconvex Economic Load Dispatch Problem," Przeglad Elektrotechniczny. pp. 139-143, 11-Jul-2013.

[8] M. N. Abdullah, M. A. Ismail, A. Azmi, N. H. M. Radzi, and J. J. Jamian, "Economic and Emission Load Dispatch Solution via Artificial Bee Colony Algorithm,” Adv. Sci. Lett., vol. 23, no. 11, pp. 11158-11161, Nov. 2017.

[9] M. N. Abdullah, A. F. A. Manan, J. J. Jamian, S. A. Jumaat, and N. H. Radzi, "Gbest Artificial Bee Colony for Non-convex Optimal Economic Dispatch in Power Generation," Indones. J. Electr. Eng. Comput. Sci., vol. 11, no. 1, p. 187, Jul. 2018. 
[10] N. A. Rahmat, I. Musirin, and A. F. Abidin, "Differential Evolution Immunized Ant Colony Optimization (DEIANT) Technique in Solving Economic Emission Dispatch," in 2013 International Conference on Technology, Informatics, Management, Engineering and Environment, 2013, pp. 198-202.

[11] Z. M. Yasin, N. F. A. Aziz, N. A. Salim, N. A. Wahab, and N. A. Rahmat, "Optimal Economic Load Dispatch using Multiobjective Cuckoo Search Algorithm,” Indones. J. Electr. Eng. Comput. Sci., vol. 12, no. 1, p. 168, Oct. 2018.

[12] N. Karthik, A. K. Parvathy, and R. Arul, "Non-convex Economic Load Dispatch using Cuckoo Search Algorithm," Indones. J. Electr. Eng. Comput. Sci., vol. 5, no. 1, p. 48, Jan. 2017.

[13] S. Mohseni, R. Gholami, N. Zarei, and A. R. Zadeh, "Competition Over Resources: A New Optimization Algorithm Based on Animals Behavioral Ecology," in Proceedings - 2014 International Conference on Intelligent Networking and Collaborative Systems, IEEE INCoS 2014, pp. 311-315, 2014.

[14] R. Gholami, S. Mohseni, B. Zakeri, and H. Abedi, "Driving Point Impedance Restriction in Synthesis of Linear Antenna Arrays using Competition over Resources Optimization Algorithm," in 2014 4th International Conference on Computer and Knowledge Engineering (ICCKE), pp. 414-419, 2014.

[15] R. Gholami, B. Zakeri, S. Mohseni, and H. Abedi, "Synthesis of Aperiodic Linear Antenna Arrays Based on Competition over Resources Optimization," in 2014 IEEE Asia-Pacific Conference on Applied Electromagnetics (APACE), pp. 171-174, 2014.

[16] A. Azmi, S. M. Zali, M. N. Abdullah, and M. F. N. Tajuddin, "Potential Competitive over Resources (COR) Optimization Method to Solve Economic Load Dispatch Problem," J. Electr. Syst., vol. 12, no. 3, pp. 529-540, 2016.

[17] Z. N. Zakaria, A. Azmi, M. S. Laili, S. A. Syed Jamalil, and M. H. Sulaiman, "An Extension of Particle Swarm Optimization (E-PSO) Algorithm for Solving Economic Dispatch Problem," in Proceedings - 1st International Conference on Artificial Intelligence, Modelling and Simulation, AIMS 2013, 2014.

[18] K. T. Chaturvedi, M. Pandit, and L. Srivastava, "Particle Swarm Optimization with Time Varying Acceleration Coefficients for Non-Convex Economic Power Dispatch," Int. J. Electr. Power Energy Syst., vol. 31, no. 6, pp. 249-257, Jul. 2009.

[19] B. Mahdad and K. Srairi, "Interactive Gravitational Search Algorithm and Pattern Search Algorithms for Practical Dynamic Economic Dispatch," Int. Trans. Electr. Energy Syst., vol. 25, no. 10, pp. 2289-2309, Oct. 2015

[20] M. H. Sulaiman and M. R. Mohamed, "Solving Economic Dispatch Problems Utilizing Cuckoo Search algorithm," in Proceedings of the 2014 IEEE 8th International Power Engineering and Optimization Conference, PEOCO 2014, no. March, pp. 89-93, 2014.

[21] M. Modiri-Delshad and N. A. Rahim, "Solving Non-Convex Economic Dispatch Problem via Backtracking Search Algorithm," Energy, vol. 77, pp. 372-381, Dec. 2014.

[22] Z. L. Gaing, "Particle Swarm Optimization to Solving the Economic Dispatch Considering the Generator Constraints," IEEE Trans. Power Syst., vol. 18, no. 3, pp. 1187-1195, 2003.

[23] A. I. Selvakumar and K. Thanushkodi, "A New Particle Swarm Optimization Solution to Nonconvex Economic Dispatch Problems," IEEE Trans. Power Syst., vol. 22, no. 1, pp. 42-51, Feb. 2007.

[24] S. K. Nayak, K. R. Krishnanand, B. K. Panigrahi, and P. K. Rout, "Application of Artificial Bee Colony to Economic Load Dispatch Problem with Ramp Rate Limits and Prohibited Operating Zones," in 2009 World Congress on Nature \& Biologically Inspired Computing (NaBIC), pp. 1237-1242, 2009.

[25] I. Ciornei and E. Kyriakides, "A GA-API Solution for the Economic Dispatch of Generation in Power System Operation," IEEE Trans. Power Syst., vol. 27, no. 1, pp. 233-242, Feb. 2012. 